\title{
电针“足三里”穴对猫肌肉机械感受器 及传入神经活动的作用
}

谭德培张淑洁毛建萍

（中国科学院上海生理研究所）

根据沈阳医学院针床组的材料 ${ }^{[1]}$, 祖国医学记载的经穴, 大多数位于神经分枝的末端, 穴位 下有丰厚的深部组织. 江振裕等 ${ }^{[2]}$ 指出，封闭支配 “合谷”穴的皮神经不影响针刺“合谷”穴引 起的镇痛效应，而用普鲁卡因浸润麻醉“合谷”穴的深部组织, 针刺镇痛效应即不再出现. 由此 可见, 深部组织的传入信号在针刺镇痛中的重要作用. 近年来我们 ${ }^{[3,4]}$ 在猫胫前肌神经上用剥 制神经细束记录单位传人放电的方法研究了针刺对肌肉的, 包括牵张和压力感受器在内的各 类机械感受器对针刺的反应, 发现它们都可被手针刺激所兴奋. 进一步对胫前肌压力感受器 的观宗表明,它们比较地集中在“足三里”穴附近,其传人神经纤维(在有䯈軗纤维范围内)以第 二类较多. 有些由无链䖝纤维支配的对重压反应的感受器, 不仅当针刺其感受野并提、插、捻、 转时产生传入放电, 而且留针在肌肉中时放电仍继续,许多单位在起针后尚可维持长时间的后 放电, 有的长达数小时. 目前针麻临床更常用电针刺激. 本文分析电针 “足三里”穴对肌肉机 械感受器及传入神经的作用.

\section{一、方法和结果}

用我们以前使用的同样的方法 ${ }^{[3,4]}$ 剥制猫胫前肌神经的纤维细束，记录其单位传人放电. 电针刺激的有效电极系插人胫前肌相当于“足三里”穴(按姜凯采等) ${ }^{[5]}$ 的针尒针. 无效电极为 夹住胫前肌附近组织的金属夹. 刺激强度调节至使肌肉产生中等程度的收缩. 胫前肌固定在 “最大生理长度” (在正常关节运动范围内的最大伸长长度). 电针持续 2 分钟, 频率为 5 赫及

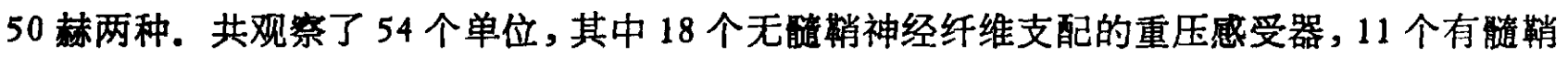
神经纤维支配的压力感受器, 15 个肌棱和 10 个腱器官.

1. 无随鞘神经纤维支配的重压感受器共观察 18 个单位, 其传入纤维的传导速度为 0.2-1.68 米/秒, 其中 9 个单位的压力感受野位于 “足三里”穴周围 1 厘米的范围内. 针刺其 感受野皆可引起传入放电. 大多数单位无自发放电, 但少数单位在多次重压感受野后产生持 续放电. 单个电震刺湤“足三里”穴仅引起一个单位兴奋, 此单位之感受野位于 “足三里”穴附 近,所用之刺激电流强度为 1.6 毫安. 另三个单位, 其感受野不在“足三里”穴附近, 电针“足三 里”穴时无放电, 如针刺入其感受野进行刺激,则可引起其传入神经纤维兴奋,所用之刺激电流 各为 $8 、 4.2 、 3.4$ 毫安. 以上 4 个单位当以 5 赫或 50 赫频率的电刺激加在 “足三里” 穴或感受 野时, 可产生 0.6-2.6 冲动/秒的放电. 对其余 14 个单位, 电针强直刺激“足三里”穴 2 分钟不 
引起其放电或不能显著改变其自发放电频率.

2. 有醚䊑神经纤维支配的压力感受器 共观察 11 个单位, 其中 6 个单位的压力感受野 位于“足三里”穴周围 1 厘米的范围内. 这些单位无自 发放电，压迫感受野引起 11.3-33 冲动/秒的传入放 电. 10 个单位属于第二类纤维, 1 个单位未测传导速 度. 当刺激神经或 “足三里” 穴引起肌肉单收缩时, 除 1 个外全部单位产生 1 个或几个传人放电. 当以 5 赫或 50 赫频率刺激 “足三里” 穴引起肌肉强直收缩时 产生重复放电, 其放电频率低于压迫感受野时产生的. 5 赫刺激时的放电频率为 $0.3-5.8$ 冲动/秒, 50 赫时为 0.08-5.1 冲动/秒. 图 1 两种刺激频率所引起的放电 频率无具有统计意义的差别.

3. 肌梭 共观察 15 个单位, 2 个单位由一类神 经纤维支配, 13 个单位由二类神经纤维支配. 有些单 位当肌肉松驰时有自发放电, 另一些在肌肉松弛时虽 无放电, 但当把肌肉固定在 “最大生理长度” 时即产生 放电. 以 5 赫或50赫频率刺激“足三里”穴对不同单位 产生的作用也不同: 有的单位放电频率比刺激前降

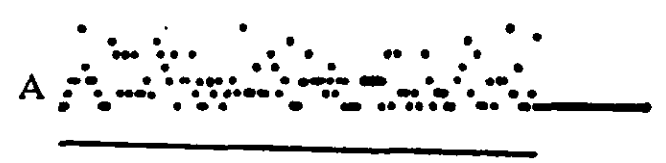

B
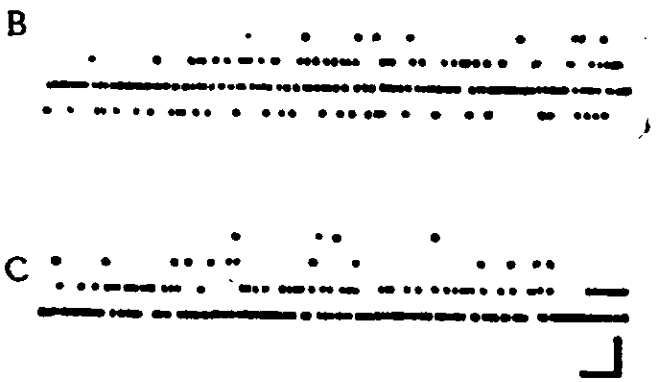

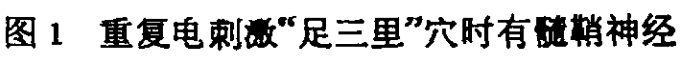
纤维支配的压力感受器的放电

全部记录为单位放电的密度序列直方图, 单位放 电由 JSY-1 型电子计算机处理. 各点的纵向位 置代表 200 旁秒内的放电数. 纵线校正: 4 个放 电. $A$ 表示压迫策受野引起的放电. “一”表示

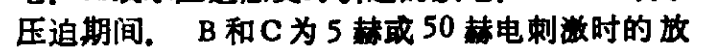
电. 时标: $A$ 为 8 秒, B 和 C 为 16 秒 低,有的则增加,少数单位放电频率无显著变化(图 2).

4. 腱器官共观察 10 个单位, 2 个单位由一类神经纤维支配, 8 个单位由二类神经纤 维支配. 1 个单位当肌肉松驰时有自发放电, 其他单位当肌肉处于“最大生理长度”时产生放
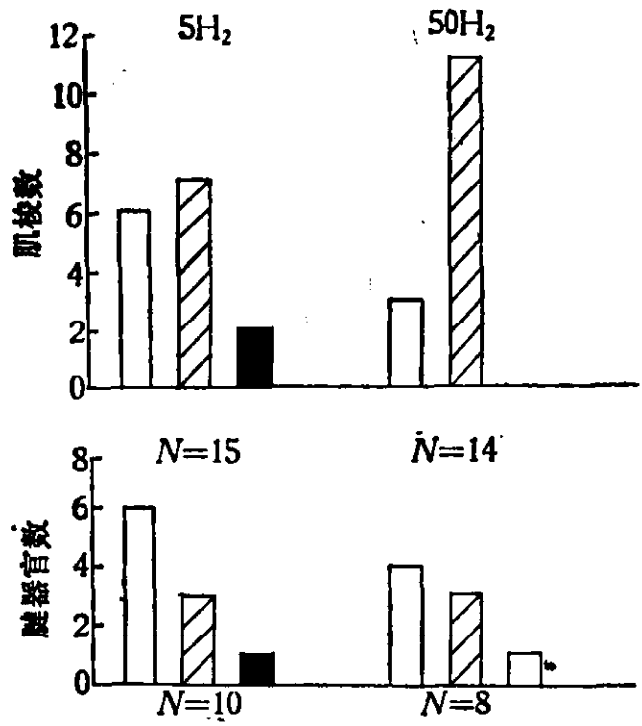

$\square$ 放电增加 而放电减少

放电不变

因 2 以 5 赫或 50 赫电刺激“足三里”穴时 胫前肌肌棱 (A) 和腱器官 (B) 放电频率 的改变

电. 5 赫或 50 赫频率刺激“足三里”穴对不同腱器官单 位的作用也不同: 有的放电比刺激前增加, 有的减少， 1 个单位放电频率无显著改变(图 2).

我们还观察了电针刺激“足三里”穴及离“足三里” 穴不同距离的胫前肌时在神经干上记录到的动作电 位. 如刺激加在 “足三里”穴处, 则刺激电流为 0.5 豪 安左右即可在神经干上记录到较小的动作电位, 增加 刺激强度动作电位幅度亦随之增加. 最大动作电位幅 度相当于最大刺激加在神经干上引起的动作电位的 $1 / 3-1 / 2$. 实际上电针刺激神经进入胫前肌处 (“足三 里”穴非常靠近此部位) 引起的动作电位最大, 当刺激 电极向两端移开时, 动作电位就逐步变小(图 3).

\section{二、讨 论}

Bessou 和 Laporte ${ }^{[6]}$ 及 Houk 和 Henneman ${ }^{[7]}$ 曾 观察到肌梭和腱器官在肌肉产生强直收缩时, 有的产 生比收缩前更高频率的传入放电, 有的则放电频率降低. 在我们的实验中也看到类似的现象. 这可能是因为电针兴奋的这部分肌纤维离所观察单位的距离不同之故. 


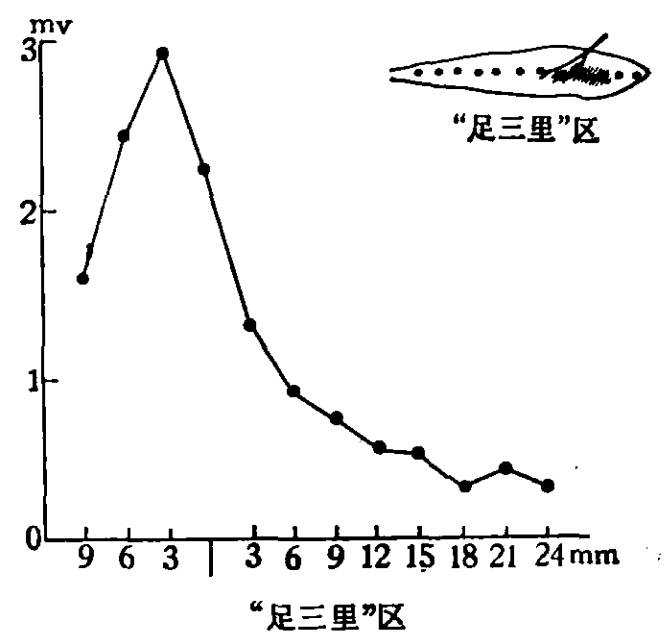

图 3 当电针沿腓肠肌级轴各个点进行刺激时在腓肠 肌神经上记录到的复合动作电位的幅度

各点间距为 3 豪米. 纵座标: 从腓肠肌神经上记录到的

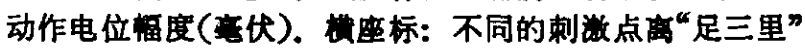
穴的距离(毫米). 右上角插图示各刺部点的位置

电针刺激“足三里”穴, 不仅由于引起肌肉收缩而改变牵张及压力感受器的活动, 并且亦可 直接兴奋肌肉神经, 因为支配胫前肌的神经即在 “足三里” 穴附近进入肌肉. 电刺激首先兴奋

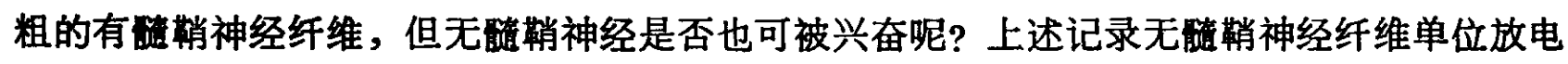
的结果显示, 电针刺激“足三里”穴直接兴奋无酭輎神经纤维的机会甚少,少数无髄䊑神经纤维 虽可被电针刺漖其感受野所激活, 但所需强度很大, 以这样的强度刺激人的肌肉, 可能是人所 难以忍受的. 然而手针刺激无酷䊑神经纤维支配的压力感受野, 经常可以引起其传入放电.

\section{三、小 结}

电针刺潡“足三里”穴,一方面可直接兴奋胫前肌神经的部分较粗的纤维，另一方面，由于 电针引起肌肉强直收缩而改变该肌肉各类机珹感受器的活动. 我们所观察的绝大多数有醚鞘 神经纤维支配的压力感受器, 肌肉松弛时无自发放电, 电针刺激时有传人放电. 肌棇和腱器 官，当肌肉处于“最大生理长度”时即有放电，电针刺激使有些晕张感受器放电增加，另一些则 放电减少. 无碳輎神经纤维支配的重压感受器, 手针刺激感受野可引起传人放电, 但能直接被 电针激活的极少. 电针引起肌肉强直收缩也不能使其放电或显著改变其自发放电频率.

[1] 汭阳医学院针麻组,针刺麻醉原理的探讨, 人民口生出版社, 1974, 68 .

[2]江振裕等,中国科学, 1973, 2: 157 .

[3] 到仁榆等,科学通报, 18(1973), 184 .

[4] 堷仁榆等,动物学报, 24(1978), 21 .

[5] 撉凯采等, 上海中医学院学报, $1960,1: 57$.

[6] Bessou, P. \& Laporte, Y., Symposium on Mussle Receptors., Hong Kong University Press, $1962,105$.

[7] Houk, J. \& Henneman, E., J. Neurophysiol., 30 (1967), 466. 